\title{
Modeling spatial and temporal variations in soil moisture in China
}

\author{
LI MingXing ${ }^{1}$, MA ZhuGuo $^{1 *} \&$ NIU Guo-Yue ${ }^{2}$ \\ ${ }^{1}$ Key Laboratory of Regional Climate-Environment for East Asia, Institute of Atmospheric Physics, Chinese Academy of Sciences, Beijing 100029, \\ China; \\ ${ }^{2}$ Biosphere 2 Earth Science, University of Arizona, Tucson 85738, Arizona, USA
}

Received December 9, 2010; accepted March 25, 2011; published online May 10, 2011

On the basis of station observations, an atmospheric field (ObsFC) was constructed for the Community Land Model version 3.5 (CLM3.5). The model (CLM3.5 driven with ObsFC, hereafter referred as to CLM3.5/ObsFC) was used to simulate soil moisture (SM) from 1951 to 2008 in China. The resulting SM was compared with in situ observations, remote-sensing data and estimations made by various land models, indicating that CLM3.5/ObsFC is capable of reproducing the temporospatial characteristics and long-term variation trends of SM over China. Using an in situ observation-based forcing field improves the simulation of SM. Analysis of SM simulated using CLM3.5/ObsFC shows that the overall spatial pattern of SM was characterized by a gradually decreasing and alternating distribution of arid-humid zones from the southeast to northwest. Regionally averaged SM was the driest over southern Xinjiang Province and western Inner Mongolia, while the most humid regions were located over the Northeast Plain, Jianghuai region and the Yangtze River basin. The long-term variation trends of SM were generally characterized by increases in arid and humid regions and decreases in semiarid regions. Moreover, the variation was relatively intense from the mid-1970s to the mid-1990s in the arid region. The time series was more stable in the humid region except for a period near 1970 and after the year 2003. A downward trend was most prominent in the semiarid region from the 1990s to the end of the time series. For 1951-2008, in the arid, semiarid and humid regions, the SM volume percentage changed by $2.35,-1.26$ and 0.08 , respectively. The variation trends and intensity remarkably differed among the different regions, with the most notable changes being over the arid and semiarid regions north of $35^{\circ} \mathrm{N}$.

soil moisture variation, spatial and temporal characteristics, CLM3.5, China

Citation: $\quad$ Li M X, Ma Z G, Niu G Y. Modeling spatial and temporal variations in soil moisture in China. Chinese Sci Bull, 2011, 56: 1809-1820, doi: $10.1007 / \mathrm{s} 11434-011-4493-0$

Soil moisture (SM) is one of the most important physical variables for characterizing the status of the land surface. SM modulates the water and energy budget balances of the land surface and the transfer of water and thermal energy between the lower atmosphere, and the land surface. Changes in SM can alter the soil's thermal capacity and surface albedo, leading to changes in the water and thermal balances between the lower atmosphere and the land surface. These changes are critical to synoptic meteorology and climatology. Namias in 1958 [1], noted the effect of SM anomalies on seasonal changes in general circulation. A test

*Corresponding author (email: mazg@tea.ac.cn) of the importance of the water cycle to general circulation employing a global climate model that incorporated land surface water cycling showed that SM variations appreciably affect space-time variations in atmospheric circulations [2]. Research in 2003 by Koster et al. [3] supported the mechanism of feedback between SM and precipitation on regional and continental scales. SM alters the processes of the water cycle between the land surface and the atmosphere, influencing precipitation, energy-cycle processes, and temperature [4]. Dai et al. in 1999 [5], demonstrated that $\mathrm{SM}$ reduces the diurnal temperature range in the lower atmosphere via evaporative cooling. In addition, SM is a relatively slowly varying component, having several months of "memory" of climatic information [6]. The Global Land- 
Atmosphere Coupling Experiment revealed the correlation between variations in regional SM and precipitation on various spatial and temporal scales. SM is the dominant aspect that controls precipitation over the dry-wet climatic transition zones in the Northern Hemisphere, and it has the same functionality as that of sea surface temperature in the equatorial eastern Pacific El Niño-La Niña cycle. SM monitoring in these "hot" spots will improve the forecasting of summer precipitation [7]. Despite greater focus being directed to the effects of SM on weather forecasts and climate predictions, the lack of observations with long temporal continuity and high spatial resolution hinders the advancement of research on SM space-time characteristics and climatic effects [8].

Despite the critical importance of in situ observations to climate modeling and validation, observational research has focused only on small or regional scale space-time variations in SM scales and not continental or global scales. Therefore, the limitations of a sparse spatial distribution and short temporal coverage of SM data continue to be problematic $[6,9,10]$. In recent years, satellite observations have greatly improved; however, the retrieved data reflect only the moisture status of the surface soil layer (upper $\sim 5 \mathrm{~cm}$ ). In addition, the accuracy of these measurements has a strong dependence on the retrieval model that is used because only indirect observations can be made [11]. Numerical simulation is another approach to investigating SM variations. For instance, the Community Land Model (CLM) has been applied extensively in studies of land surface processes in China. A number of studies have evaluated and validated the capability of the CLM to represent variations in land surface processes [12]. Du et al. analyzed the spacetime characteristics and variation trends against the background of global change with a CLM3.0 simulation [13]. Wang and Zeng discussed the effects of the quality of meteorological forcing data (such as precipitation and temperature) on the simulations of variables in the land surface water cycle [14]. Numerical simulations of SM contain uncertainty because, as many studies have implied, the accuracy of SM simulations depends critically on the quality of atmospheric forcing data and the description of land surface processes [15-17]. While data assimilation methods combine the advantages of numerical simulations and in situ observations, these methods are unable to reproduce the long-term history of SM variations because of the short time span of such observations $[18,19]$. In an attempt to apply the observational record, we constructed an atmospheric forcing field using observations (known as ObsFC) for the CLM version 3.5 (CLM3.5), with high spatial resolution. Next, SM was simulated for China during the period 1951-2008 using CLM3.5, which was forced with ObsFC (hereafter referred to as CLM3.5/ObsFC). We evaluated the quality of ObsFC via a comparison with in situ observational data and examined the capability of CLM3.5 to represent the variations in SM in China. The space-time characteristics of SM and its long-term variation trends in China were then ana- lyzed. Finally, we addressed the effects of atmospheric forcings on the SM simulation and the deficiency of CLM3.5 in the application of SM simulations for China. Some potential directions for improvement to the description of CLM3.5 are also proposed.

\section{Model and data}

\subsection{CLM3.5 description}

The CLM was developed from the Common Land Model and the Land Surface Model (LSM) of the National Center for Atmospheric Research, and it serves as the land surface component of the Community Climate System Model. The CLM merged both the advanced methodology and comparatively sophisticated representations of physical processes found within land models such as the LSM [20], IAP94 [21] and BATS [22]. The CLM has also improved some descriptions of SM, frozen soil and other physical processes over previous models and introduced a river transport model. In the vegetated land unit, the concept of plant functional type was adopted to represent the heterogeneity of a grid cell. These substantial improvements describe the development of CLM version 3.0. In terms of water and energy cycles, a number of studies have shown that the simulations of CLM3.0 were greatly enhanced, compared with the previous version [23-26]. However, the simulations of the water cycle had large biases for variables such as SM. Therefore, researchers have continued to strive for further improvement and development of the land surface dataset and representations of hydrological processes. Lawrence et al. refined land surface data with products from MODIS [26] and improved the representation of canopy interception [27,28]. Niu et al. [29-31] improved the resolution of evaporation and available soil water. Furthermore, the processes of runoff, groundwater, carbon and nitrogen cycles, and frozen soil were introduced or improved in the update of CLM3.0. The improved CLM3.0 (known as CLM3.5) greatly enhanced water cycle modeling [32,33]. The latest version, CLM4.0, adopted a modified resolution of the Richards equation, used a soil evaporative resistance function instead of a resistance coefficient and improved the definition of the lower boundary condition to directly couple the soil water and ground water [34,35]. Moreover, CLM4.0 accounted for the effects of canopy litter and soil organic matter on soil water transfer [36]. The model also enhanced the representation of the snow model [37] and the dynamic vegetation and the urban models. In this study, the exploration of SM variation in China is based upon the CLM3.5 simulation because CLM4.0 had not yet been released. Future work will use CLM4.0.

\subsection{Atmospheric forcing field and land surface data}

Aside from the representation of physical processes, the quality of the atmospheric forcing field is a critical component 
that controls the accuracy of land surface simulations under an off-line model [23]. Because the application of in situ observations is critical to the enhancement of the atmospheric forcing field, we constructed ObsFC, which consists of four status variables (air temperature, atmosphere pressure, wind speed and specific humidity) and two flux variables (precipitation and radiation). The horizontal resolution of ObsFC is approximately $0.5^{\circ} \times 0.5^{\circ}$ and the temporal resolution is every 3 hours. The data span is 58 years from 1951 to 2008. The radiation flux was taken from Princeton's dataset [38] because it has a short time span of observations and sparse spatial distribution $[39,40]$. We also incorporated the ready land surface data released with CLM3.5, which includes topography, soil properties, plant functional types, a vegetation physiological parameter and land use.

\subsection{In situ SM, remote-sensing retrieval and other model-simulated SM data}

Comparisons of CLM3.5-simulated SM with in situ observations, remote-sensing retrieval data and the SM simulated by different land models using various atmospheric forcings can contribute to evaluations of CLM3.5/ObsFC simulations. Therefore, we used in situ data from 143 sites to evaluate the spatial pattern of SM in China for the period 1990-1999 and the variation correlation over northeastern China from 1990 to 2000 . Because remote-sensing retrieval data can capture the spatial patterns of SM variations, we compared the CLM3.5/ObsFC simulations with two retrieval datasets that are used extensively: AMSR-E (Advanced Microwave Scanning Radiometer for the EOS (Earth Observing System)) and ERS-2 SCAT (European Remote Sensing Satellite). In addition, comparisons among multiple sources from various models (driven by various forcings) can reduce the effects of atmospheric forcing and representations of physical processes on SM simulations, thus helping users to understand the uncertainties of the simulations and the limitations of CLM3.5 in various applications. We compared the spatial patterns of SM obtained from CLM3.5/ ObsFC, GLDAS and CPC over China.

\section{Validation and comparison}

To eliminate initialization effects and to examine the model's long-term integration ability, considering the different time scales of soil water transfer at various depths, CLM3.5 was first run for 400 years via cycling the 1951-2000 forcing data and then run from 1951 to 2008 . Consequently, the simulations of water cycle variables were output to validate and analyze the space-time characteristics of SM variations in China.

\subsection{Comparison of SM simulated by CLM3.5/ObsFC with in situ observations}

The in situ measurements of SM were collect from agrometeorological stations of the Chinese meteorological station network. The majority of these observations began in the 1980s, and measurements were made every 10 days (generally on the 8th, 18th and 28th day of each month) until the sampled soil froze during the winter. While the observational depth at most sites spanned 0-1 m, it reached a depth of $2 \mathrm{~m}$ at a few sites. The sites were distributed mainly over eastern China. Despite the coarse spatial and temporal coverage, this in situ dataset has a crucial role in model and simulation validations because it has the longest time span of any observations and the most extensive spatial coverage. The measurements for 40 sites derived from these in situ observations were validated and incorporated into the global SM dataset [9]. In this study, we processed the data for 143 sites in the period 1990-1999 (Figure 1; aberrant data values were revised using statistical methods to account for the effects of irrigation on the measurements, and we
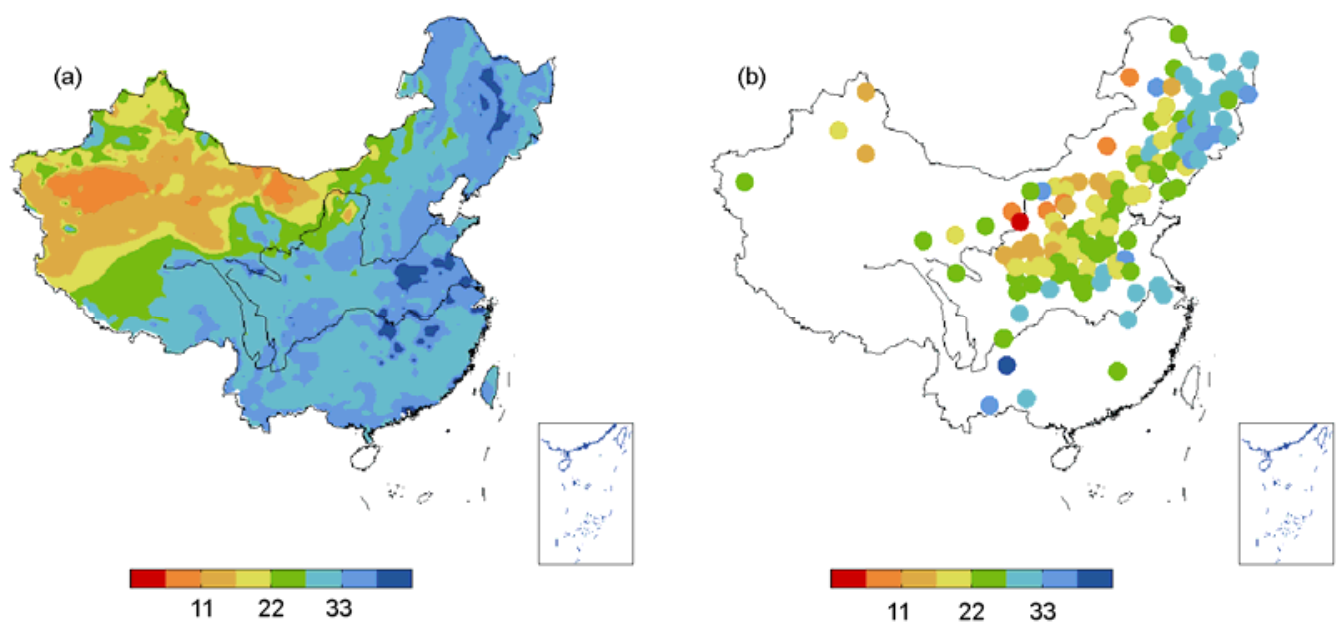

Figure 1 Spatial pattern of the averaged CLM3.5/ObsFC simulations $(0-49.3 \mathrm{~cm})$ and in situ observations (0-50 cm) for the summer (JJA) of 1990-1999 (unit: \% v/v). (a) CLM3.5/ObsFC simulations; (b) in situ observations. 
kept data from as many sites as possible). The in situ data were compared with the CLM3.5/ObsFC-simulated SM at approximately the same depth and time to compare the spatial patterns between simulations and observations.

We compared the spatial patterns of the simulated and observed SM only over the summer months (June, July and August) because the observations were suspended when the sampled soil froze (Figure 1). The results illustrate that among differing regions, changes in wet-dry SM for both simulated and observed values are basically consistent with each other. The simulated SM reproduced the alternate drywet spatial distribution pattern of SM from east to west in the northeast and also matched observations for the four sites in western Xinjiang Province in terms of relative variations. Similarly, the simulations correctly represented the region of higher SM across the Yangtze River basin. However, the spatial pattern of simulated SM drifted northwestwards in contrast with the observations, revealing systematic bias in the CLM3.5/ObsFC simulations.

In the northeast, the in situ observed SM has longer, relatively more complete and high spatial density records, allowing for the analysis of the variation correlation between the annual means of the simulated and observed SM in this region. Figure 2 shows the variations in two SM time series from 1990 to 2000. Here, the SM averaged regionally was obtained from the observations of 47 sites and the corresponding CLM3.5/ObsFC grid cells, with depths of $0-50$ $\mathrm{cm}$ (mean of five layers) and $0-49.3 \mathrm{~cm}$ (weighted mean of six layers), respectively. The two SM time series showed strong linear correlation, with a correlation coefficient of 0.837 (at the $\alpha=0.001$ level, which is statistically significant). Both of the regression coefficients were negative, indicating the decreasing trends of simulated and observed SM. In addition, the simulated variations are in phase with the observations over the study period with the exception of

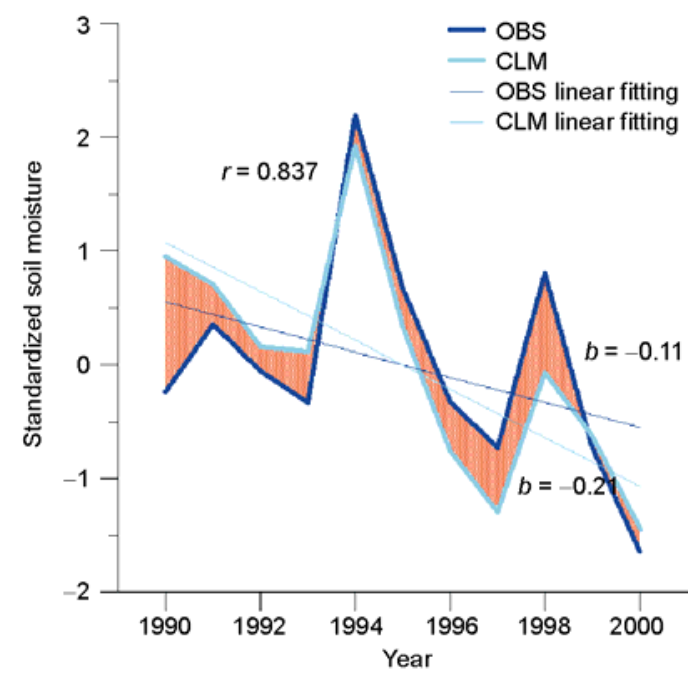

Figure 2 Comparison of the annual mean of CLM3.5/ObsFC-simulated and observed SM in the northeast for the period 1990-2000. the year 1991. The amplitudes and the amplitude variations in the two time series are also very similar.

\subsection{Comparison of CLM3.5/ObsFC-simulated SM with remotely sensed $\mathrm{SM}$}

The satellite remote-sensing observations have high spatial coverage and resolution. With the development of remotesensing technology, space-time and spectral resolutions of observations have greatly improved. These observations are highly useful for regional and global SM monitoring, and they compensate for the lack of in situ observations. Currently, two of the most commonly used satellite products of SM are provided by ERS-2 SCAT [41,42] and AMSR-E [43]. We compared the spatial patterns of SM simulated by CLM3.5/ObsFC to those observed by ERS-2 SCAT and AMSR-E.

Figure 3 shows the averaged patterns of SM observed by ERS-2 SCAT and simulated by CLM3.5/ObsFC for summer and winter during the period 1992-2000. The comparisons demonstrate reasonable consistencies between the two datasets. The data reveal that the soil was relatively wet in the plain of the mid-northeast but dry in the mountains. The soil dried gradually from east to west in Inner Mongolia, and the drier soil was distributed mainly over deserts in western Inner Mongolia and southern Xinjiang. The wetter regions of SM were located mostly in the Yangtze and Huaihe River basins. There was regional disparity in the two SM datasets mainly in the domains south of $35^{\circ} \mathrm{N}$, particularly on the southeastern Qinghai-Tibetan Plateau. There were extensive humid soil conditions in the case of ERS-2 SCAT SM, but the CLM3.5/ObsFC-simulated SM had a relatively small gradient in the areas north of $35^{\circ} \mathrm{N}$. In addition, wet-dry discrepancies were prominent in the lower Yangzi River basin and the Huaihe River basin, with ERS-2 SCAT showing drier soil but CLM3.5/ObsFC showing wetter soil. The differing definitions for surface features, such as lakes and metropolitan areas, in the two datasets possibly contributed to the disparities. In terms of seasonal discrepancies, the spatial patterns of the two SM datasets were similar in summer, but a larger dry area extending southward was indicated by the retrieved SM compared with the CLM3.5/ ObsFC-simulated SM in winter. Moreover, the CLM3.5/ ObsFC-simulated SM is significantly wetter than the ERS-2 SCAT SM in winter (relatively dry area fraction).

Figure 4 compares surface SM distributions between AMSR-E and CLM3.5/ObsFC in the dry and wet seasons during the period 2003-2008. In general, the results indicate that the dry-wet patterns were similar, particularly in the domain north of $35^{\circ} \mathrm{N}$. However, in the areas south of $35^{\circ} \mathrm{N}$, despite similar wetter areas in the two SM fields over the Huaihe River basin, the soil is drier in the case of AMSR-E and wetter in the case of CLM3.5/ObsFC over the lower Yangtze River basin (Figure 3). The soil is generally wetter in the case of CLM3.5/ObsFC, and this is particularly 

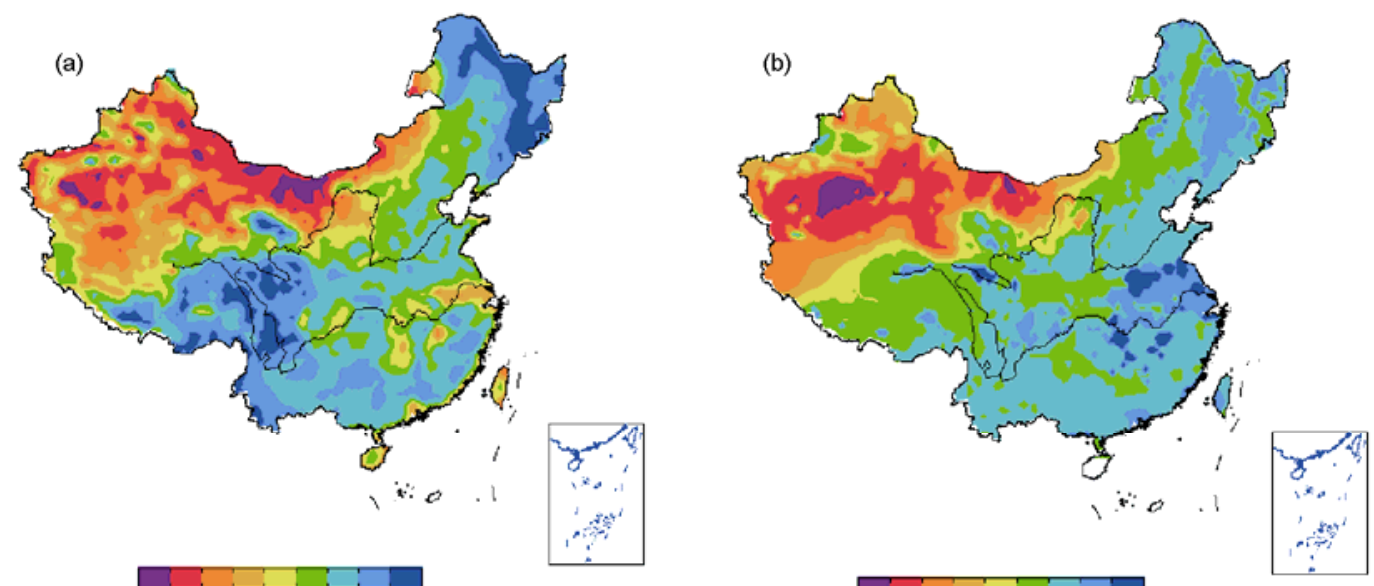

510152025303540

510152025303540
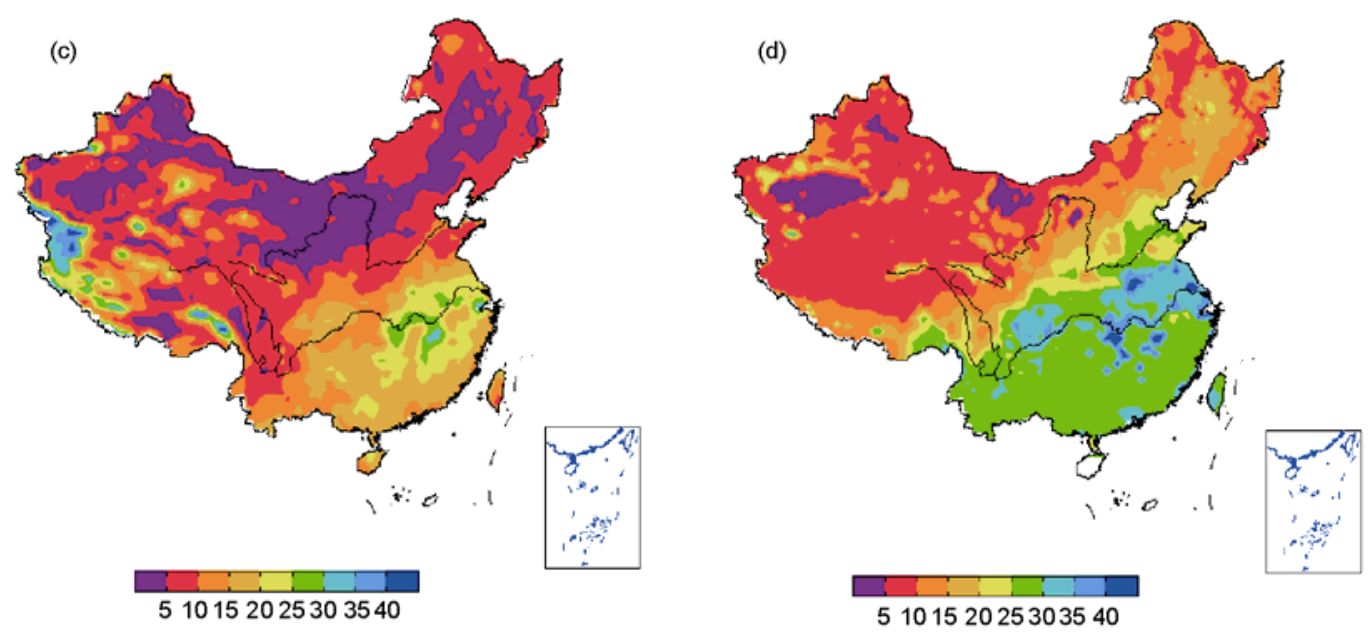

Figure 3 Spatial patterns of summer and winter SM (\% v/v) of ERS-2 SCAT (0-5 cm) and CLM3.5/ObsFC (0-4.5 cm) for the period 1992-2000. (a) summer ERS-2 SCAT SM; (b) summer CLM3.5/ObsFC SM; (c) winter ERS-2 SCAT SM; (d) winter CLM3.5/ObsFC SM.

pronounced in the eastern humid regions in terms of the absolute values. With respect to the seasonal discrepancies, the patterns were more consistent between CLM3.5/ObsFC and AMSR-E in summer than in winter. For instance, the driest region in the AMSR-E SM was located in the northeast, while the driest region in the CLM3.5/ObsFC SM remained in the northwest during the winter. On the other hand, the liquid soil water decreased more in AMSR-E than in CLM3.5/ObsFC when the soil was frozen. Similarly, the disparities of relatively wet and dry extents were salient between AMSR-E and CLM3.5/ObsFC in the lower Yangtze River basin.

\subsection{Comparison of CLM3.5/ObsFC with different models}

Land surface models are incapable of perfectly tracing SM variations, and simulations using various models are therefore discrete owing to the differences in the representation of physical processes and numerical solutions. As most land models characterize the space-time distributions and long- term variation trends, comparisons among SM simulations obtained using various models could be helpful in evaluating the basic accuracy of SM simulations [8]. We therefore evaluated the CLM3.5/ObsFC-simulated SM via comparisons with SM obtained with multiple models, such as GLDAS (Global Land Data Assimilation System [44]) and CPC (leaky bucket model [45]).

Figure 5 shows the space-time patterns of averaged SM obtained from various land models for the period 19792008. Because of different soil depths and layers among the models, we standardized the total column soil moisture using eq. (1). The standardized values were then mapped between 0 and $40 \%$.

$$
\mathrm{SM}_{\text {norm }}=\frac{\mathrm{SM}-\mathrm{SM}_{\text {min cn }}}{\mathrm{SM}_{\text {max cn }}-\mathrm{SM}_{\text {min cn }}} \times 40.0,
$$

where $\mathrm{SM}_{\text {norm }}$ is $\mathrm{SM}$ standardized between 0 and $40 \%$, $\mathrm{SM}$ is from the original simulations $\left(\mathrm{mm}^{3} / \mathrm{mm}^{3}\right)$, and $\mathrm{SM}_{\min \mathrm{cn}}$ and $\mathrm{SM}_{\max \mathrm{cn}}$ are the minimal and maximal $\mathrm{SM}$ values in China $\left(\mathrm{mm}^{3} / \mathrm{mm}^{3}\right)$, respectively.

The standardized multi-model-simulated SM demonstrated 


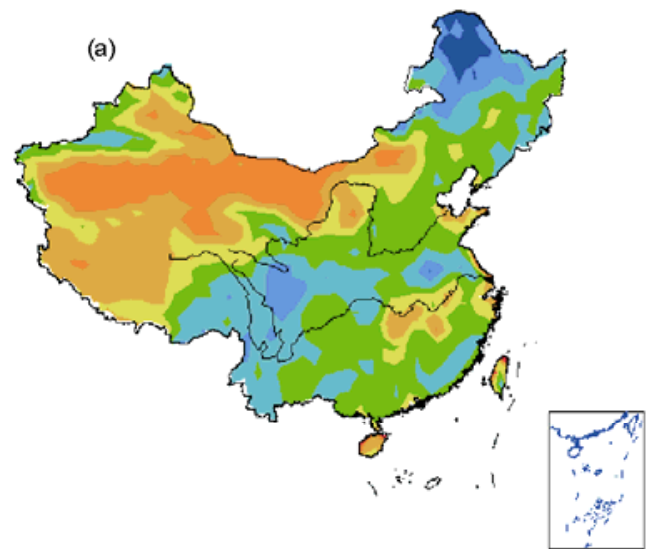

$6 \quad 8 \quad 1012141618$

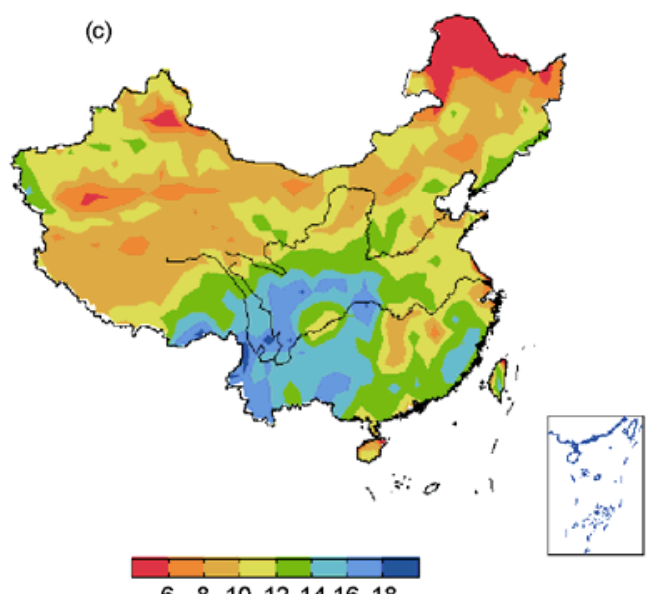

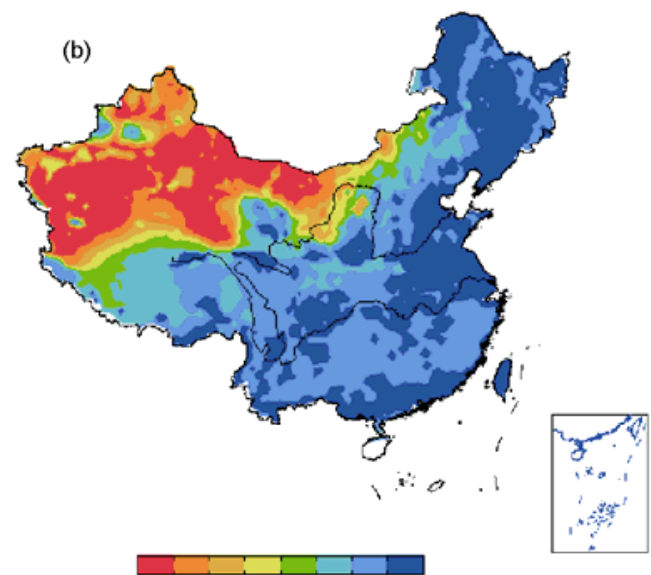

$6 \quad 8 \quad 1012141618$

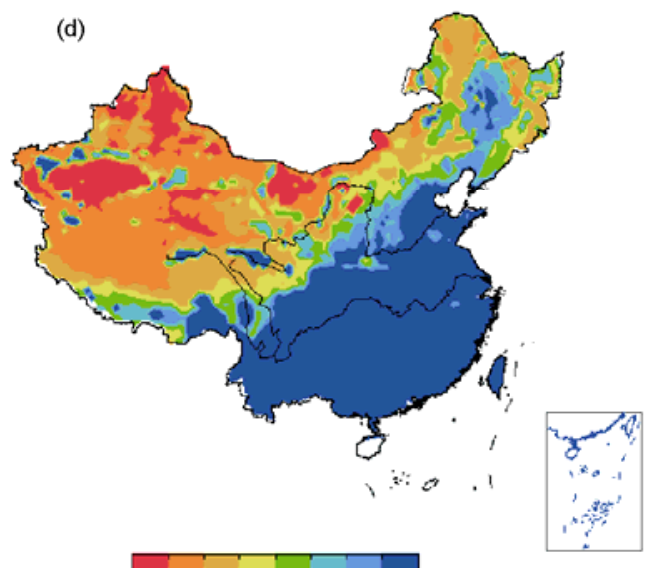

$6 \quad 8 \quad 1012141618$

Figure 4 Spatial patterns of summer and winter SM (\% v/v) of AMSR-E (0-1 cm) and CLM3.5/ObsFC (0-1.75 cm) for the period 2003-2008. (a) Summer AMSR-E SM; (b) summer CLM3.5/ObsFC SM; (c) winter AMSR-E SM; (d) CLM3.5/ObsFC SM.

the spatial characteristics of the observed SM in China. The values of SM decreased gradually from the southeast to northwest. The lower values of SM were found in the areas of western Inner Mongolia and the Tarim Basin in southern Xinjiang, while the higher SM values were found mainly for the Northeast Plain and the Huaihe and Yangtze River basins. The major disparity among the multi- model simulations was the amplitudes of SM. For instance, the SM varied between $30 \%$ and $40 \%$ in the simulations using the CLM2 and VIC models, with small regional variations. The simulations using the other four models illustrated the spatial transitions of SM in detail. The spatial characteristics of CPC SM resembled those of precipitation (with a large dry fraction) because its forcing field was composed of precipitation and temperature. The MOSIAC- simulated SM has a dry area that is too large in northern China and weak variations in the northwest. Despite having too large an absolute $\mathrm{SM}$, the NOAH-simulated SM indicated reasonably dry SM areas. The SM obtained from CLM3.5/ObsFC represented the arid and semiarid regions and the transition zone well, with accurate locations of dry and wet regions. It revealed the general characteristic of SM decreasing gradually from the southeast to northwest. The improvement of SM simulations using CLM3.5/ObsFC is associated with not only the representation of physical processes but also the application of observation-based data to atmospheric forcing. In addition to these improvements, the results of multi-forcing simulations [40] indicate that the quality of the atmospheric forcing is of critical importance to the improvement of SM simulations.

\section{Spatial patterns and space-time variation characteristics}

The spatial pattern of SM in China (Figure 6) was characterized by wetter regions in the southeast and drier regions in the northwest. In the semiarid regions, the SM increased with depth more significantly than in other regions. For example, where the surface SM (0-28.9 cm) was low, 


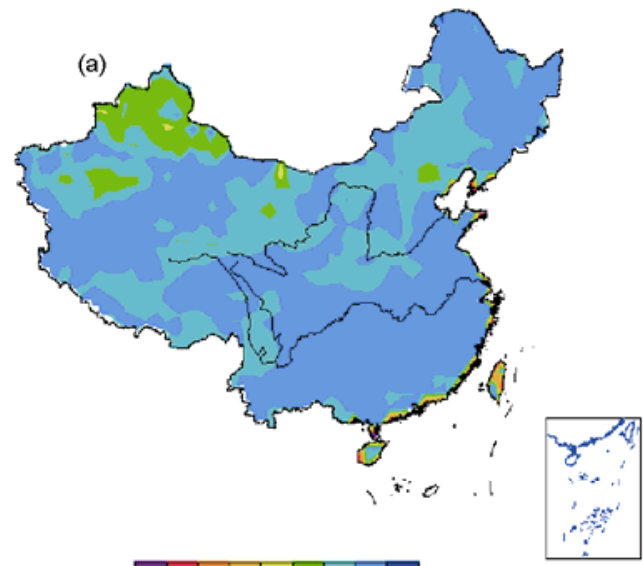

510152025303540

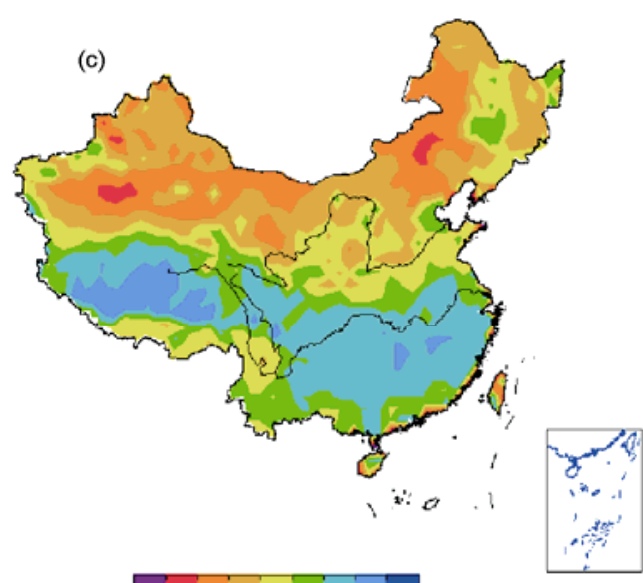

510152025303540

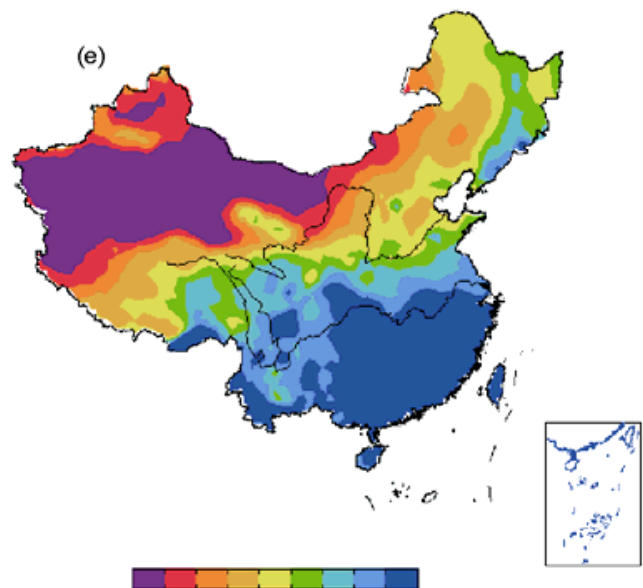

510152025303540

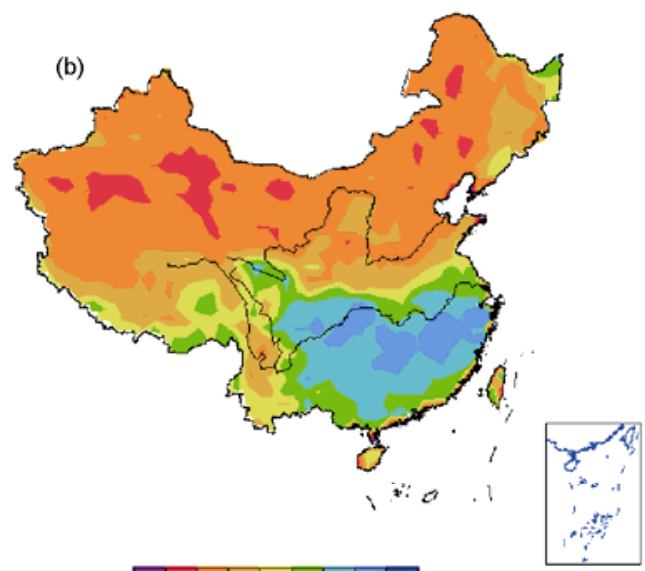

510152025303540

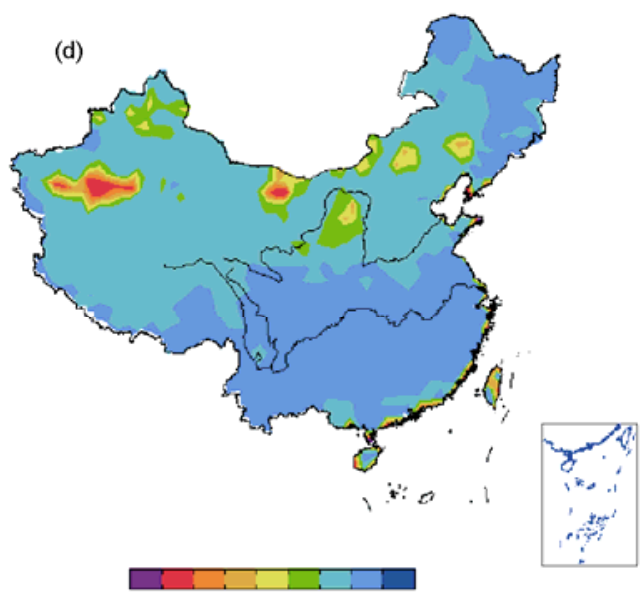

510152025303540

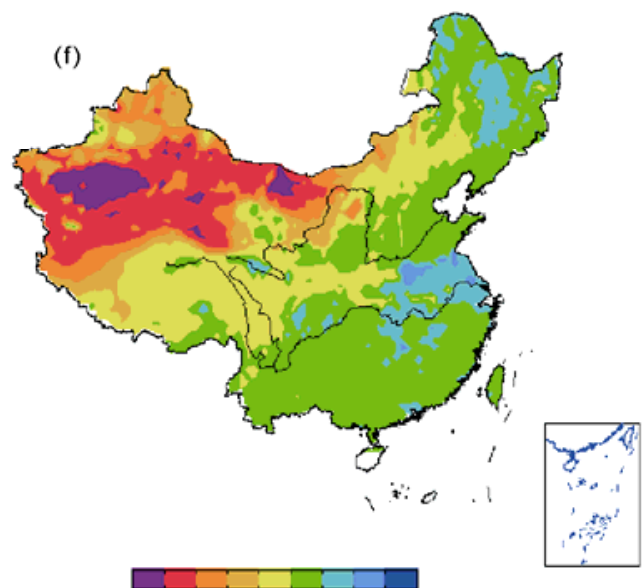

510152025303540

Figure 5 Spatial patterns of multi-model-simulated SM (\% v/v) for the period 1979-2008. (a) CLM2; (b) MOSIAC; (c) NOAH; (d) VIC; (e) CPC; (f) CLM3.5.

deeper SM (28.9-82.9 cm) increased with increasing depth. In contrast, the variations in SM with increasing depth were much weaker in the arid and humid regions. The areas with low SM were mainly in the southern portion of Xinjiang and western Inner Mongolia, with SM (in the 0-82.9 cm soil) less than $10 \%(\mathrm{v} / \mathrm{v})$ due to the low precipitation and strong radiation present in the region. The regions with hu- mid soil were mainly located on the Northeast Plain and in the Huaihe and Yangtze River basins. In some parts of the Yangtze River Basin, the annual SM exceeded $35 \%$ in the deeper soil layer $(28.9-82.9 \mathrm{~cm})$. In the dry and wet transition regions located in semiarid areas, the SM variations were characterized by swift increases with depth, especially in the areas south of $35^{\circ} \mathrm{N}$. The aforementioned space- 


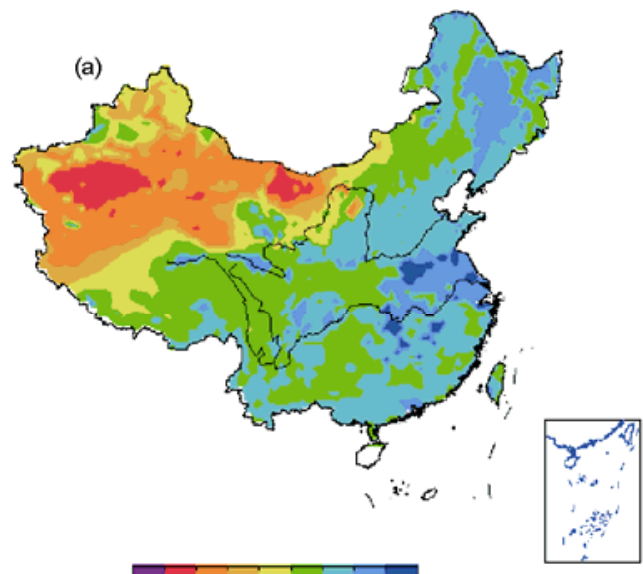

510152025303540

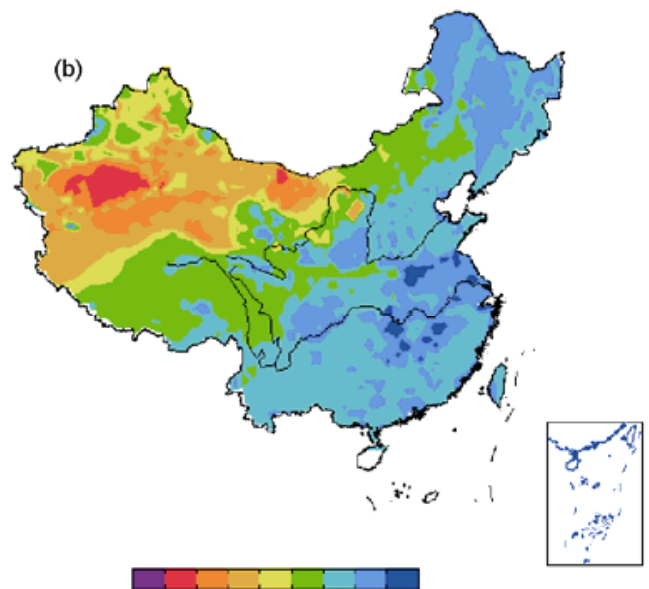

510152025303540

Figure 6 Spatial patterns of averaged annual SM (\% v/v) for the period 1951-2008. (a) 0-28.9 cm; (b) $28.9-82.9 \mathrm{~cm}$.

time features of SM simulated by CLM3.5/ObsFC were generally consistent with the results of previous studies in China [46-49].

Figure 7 shows the spatial distributions of the linear trends of annual SM for two soil layers $(0-28.9 \mathrm{~cm}$ and $28.9-82.9 \mathrm{~cm}$ ) in China during the period 1951-2008. The patterns were characterized identically by a drying and wetting alternate trend pattern from the northwest to southeast at two soil depths. The significant trends were located principally in regions north of $35^{\circ} \mathrm{N}$ (data not shown). The trend distributions indicated that the SM increased over arid regions but decreased across semiarid regions during the period 1951-2008. In the southern humid regions, the SM similarly showed relatively flat wetting trends (the regression coefficient was smaller by an order of magnitude, Figure 8). The trend features noted above are in agreement with the results of previous studies [50-52]. The statistical analysis of climatic variables [39] for the period (1961-2000) suggested four major findings: annual precipitation increased in northwestern arid regions but decreased in semi- arid regions, radiation weakened in most regions except in the eastern portion of the northwest China and most parts of central China, temperatures warmed throughout China except for the Sichuan Basin, and wind speed variations had decreasing trends over northern and eastern China. The above findings imply that SM variations were the result of a synergism of multiple climate variables that varied widely in intensity across the different climate zones [53]. However, on short time scales, precipitation appears to control the SM fluctuations [54].

The above results reveal that the variation trends and sensitivities of SM variations to climate variables varied in different regions. We therefore analyzed the regional variances of SM variations in typical arid, semiarid, and humid regions. Figure 8 shows the variations in SM $(0-28.9 \mathrm{~cm})$ and the corresponding precipitation time series for the three typical regions during the period 1951-2008. There was a wetting trend for the SM in the arid region, with an increase of 2.35 volumetric percentage points over the 58 years. The SM decreased 1.26 percentage points in the semiarid
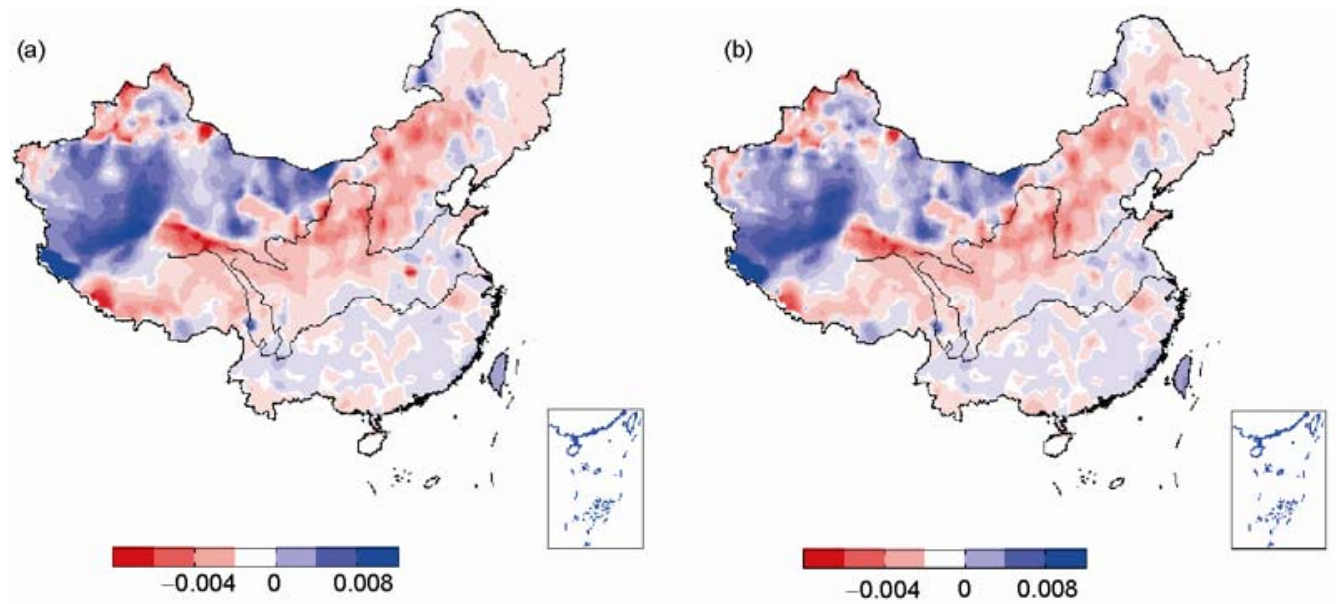

Figure 7 Spatial patterns of SM variation linear trends for the period 1951-2008. (a) 0-28.9 cm; (b) $28.9-82.9 \mathrm{~cm}$. 

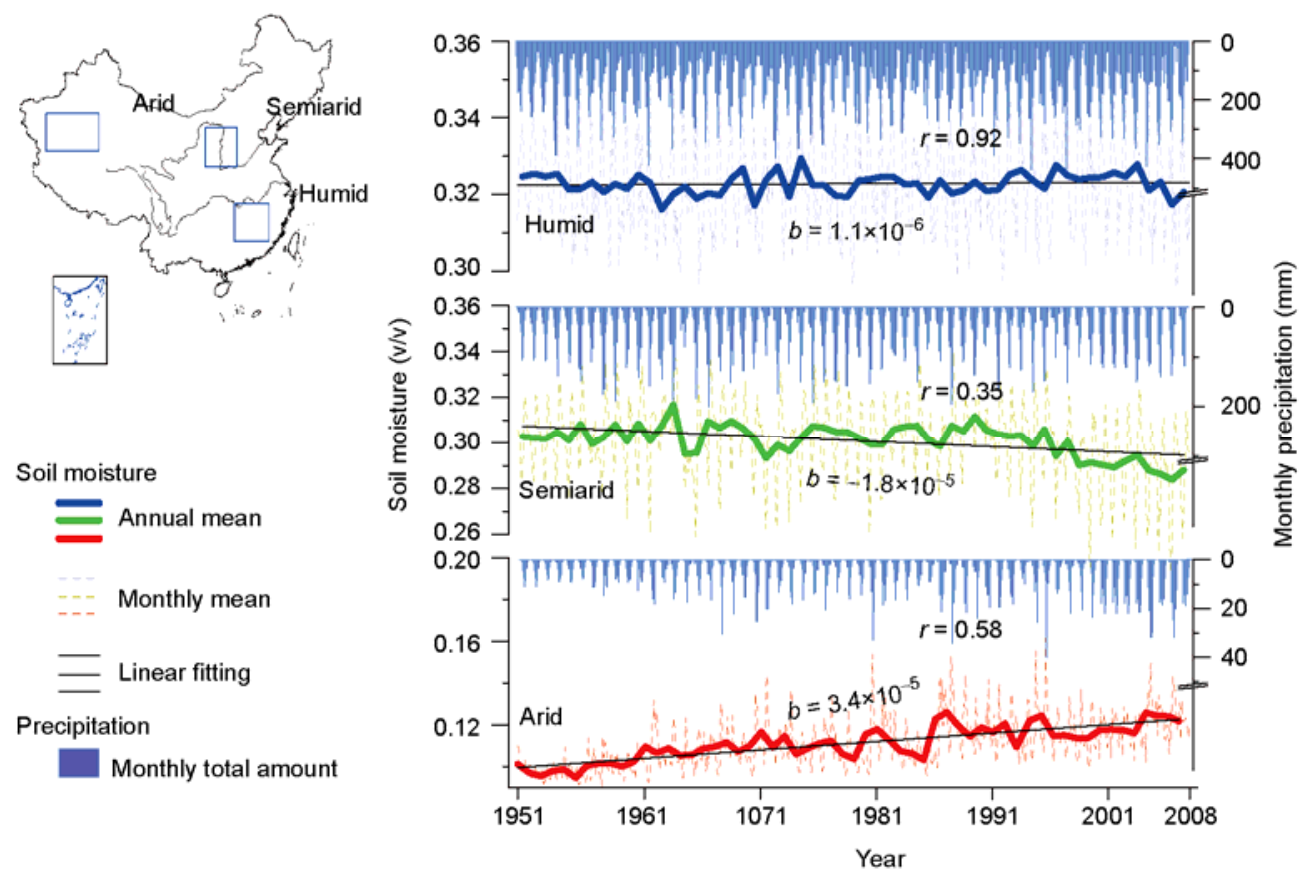

Figure 8 Comparison of SM variation trends in typical regions for the period 1951-2008. In the time series plots, $b$ is the linear regression coefficient and $r$ is the coefficient of correlation between monthly SM and precipitation.

region during the 58 years. In the humid region, the SM had a considerably weaker wetting trend; the SM increased by only 0.08 volumetric percentage points, which is less than the increase in the arid and semiarid regions by an order of magnitude. In addition, the correlations between SM and precipitation were characterized by regional discrepancies. The correlation coefficients were $0.58,0.35$ and 0.92 (with long-term linear trends not removed) in the typical arid, semiarid and humid regions, respectively. All correlation coefficients were statistically significant at the $\alpha=0.01 \mathrm{lev}$ el. The correlation coefficients implied that the effects of precipitation on the SM variations $(0-28.9 \mathrm{~cm})$ differed among various climate zones. Precipitation was the principal variable that controlled the variation trend of SM in the humid regions. The influences of evapotranspiration on SM were small because of the high SM in the region. Similarly, precipitation dominated the SM variations in the arid regions. In the arid regions, SM was close to the wilting point, a condition where water quickly becomes unavailable to evaporation after a precipitation event. Consequently, the SM variations were characterized by positive anomalies induced by precipitation. However, the dominance of precipitation weakened in the semiarid region. The combined actions of temperature, radiation, vegetation, soil properties and additional factors controlled and complicated the variations in SM [39].

Figure 9 shows the first two spatial patterns and time series of the empirical orthogonal function (EOF) analysis of SM in China for the period 1951-2008. The first eigenvector reveals the characteristics of SM variations controlled by precipitation and illustrates that the SM variation trends were in the same direction in the arid and humid regions but in the opposite direction in the semiarid regions. In addition, it shows that stronger oscillations were mainly located in the regions north of $35^{\circ} \mathrm{N}$. The expansion coefficient of the first mode implies that the spatial pattern of SM variation trends was characterized by a $20-30$-year shift, and the spatial features became more intense after the year 2000. The second eigenvector reflects the combined effects of temperature, radiation, wind and soil properties on SM variability. The sensitivity tests reveal that the SM variations that were dominated by the resultant action of temperature, radiation, wind, and other relative variables were stronger north of $35^{\circ} \mathrm{N}$, leading to an increase in SM in central and western China but a decrease in SM in the east [39]. The time series suggests that the spatial pattern of SM variation trends delineated by the second mode was relatively strong in the 1950s and 1990s. The time series also suggests that there was a dry and wet shift around 1970.

The results of wavelet analysis for the three typical regions (Figure 10) indicate that there was a 2-4-year period in the SM variations in arid regions in the 1980s. Over a period of 8-16 years, low-frequency oscillations were stronger in the early stage of the study period, while highfrequency oscillations were more obvious in the later stage. For the semiarid region, oscillations with a period of 2-4 years were prominent, with larger amplitudes during the period of the 1960s through the 1980s and after the year 2000. In addition, the 16-year oscillations became more intense with time. Similarly, the fluctuations were characterized by a 2-year period for the humid-region SM, particularly in the 1960s and 1990s. On the other hand, 4-year 

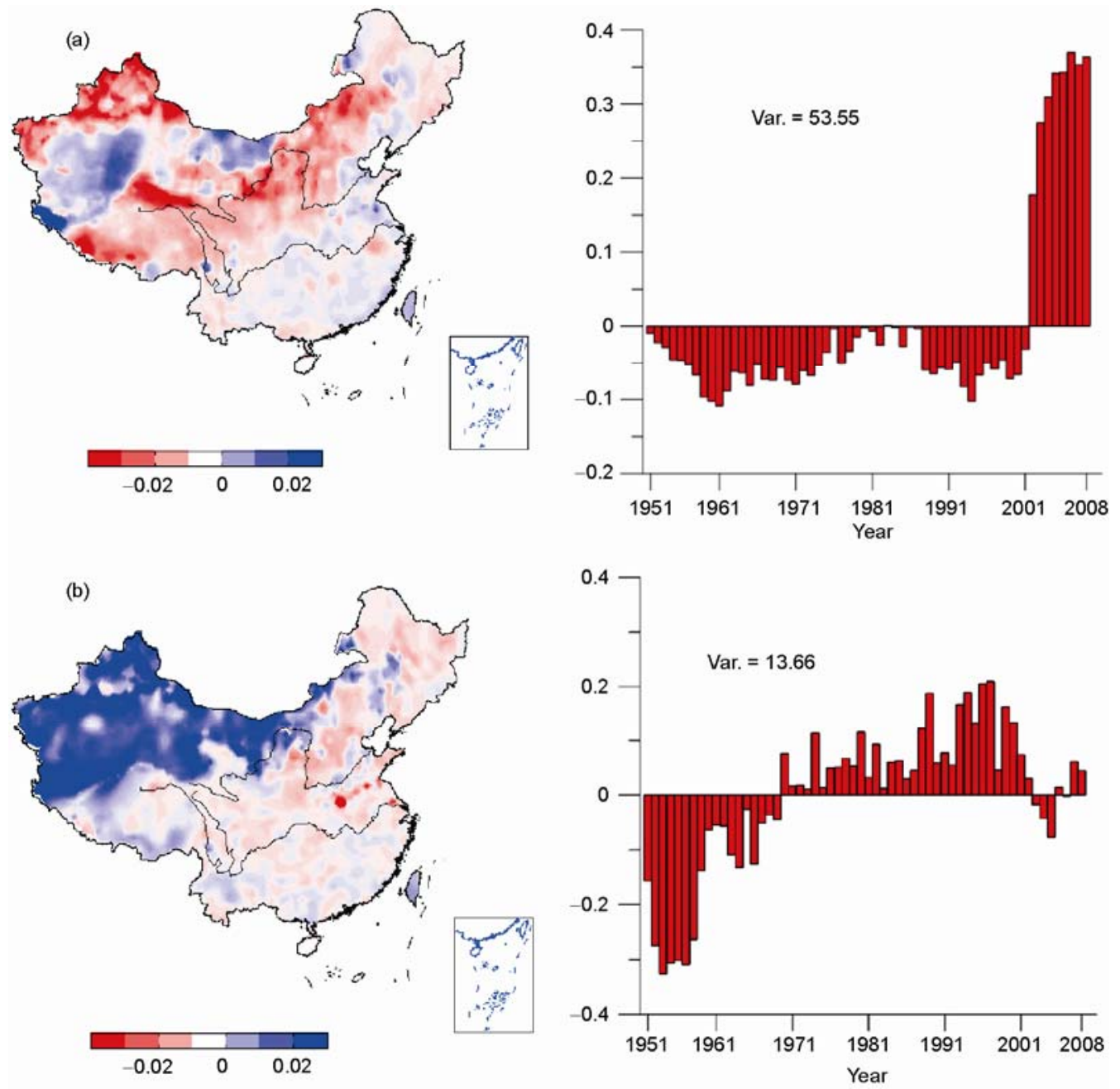

Figure 9 Spatial (left) and temporal (right) patterns of the two leading EOFs for upper SM (0-28.9 cm) from 1951 to 2008. (a) First leading EOF; (b) second leading EOF.
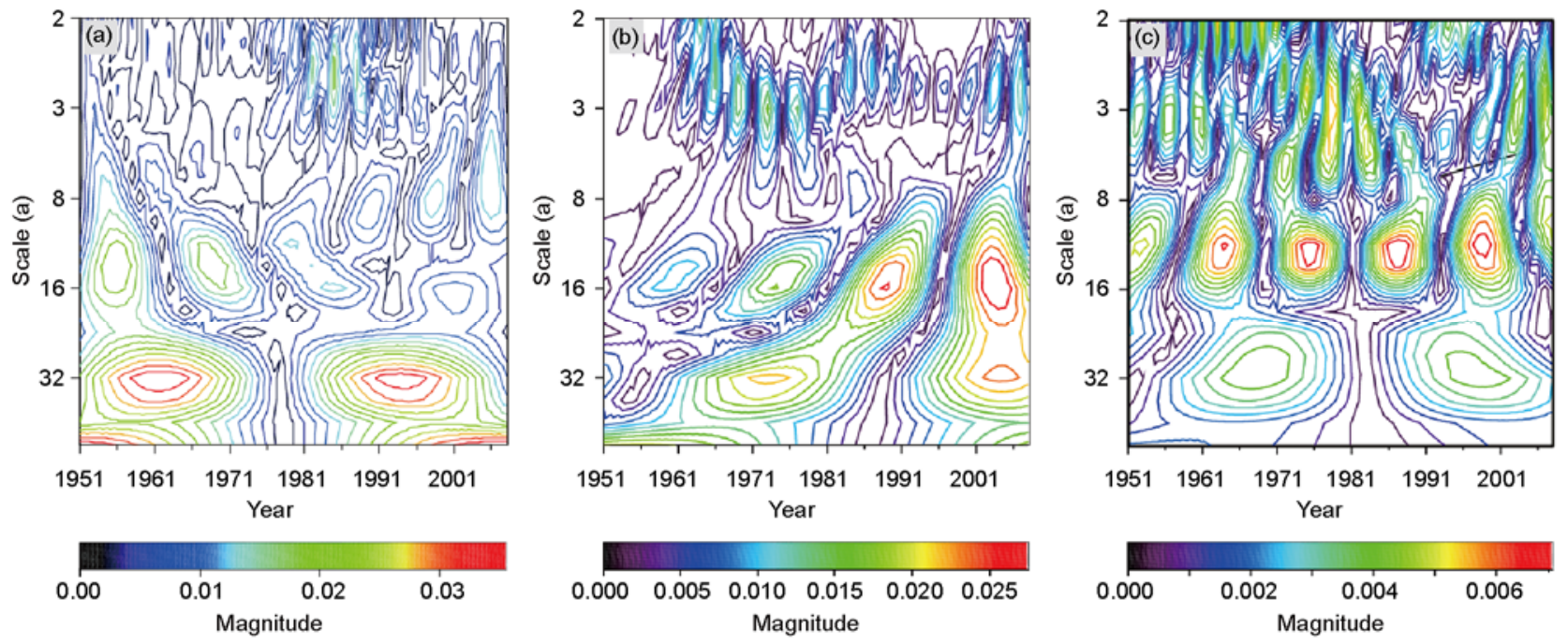

Figure 10 Wavelet analysis results for the SM in three typical regions. (a) Arid region; (b) semiarid region; (c) humid region. 
and decadal oscillations were present most prominently in the humid region. These various oscillation periods in the SM time series for multiple climate zones imply that the discrepancies among climate zones dominated the SM variations. In addition, the effects of different variables on the SM variations changed with time and climate zones.

\section{Summary and discussion}

We constructed an observation-based atmospheric forcing field for the CLM, with which CLM3.5 was used to simulate SM in China from 1951 to 2008. The resulting SM data were compared with in situ observations, remote-sensing retrieval data and simulations from other land models. The results indicate that CLM3.5/ObsFC captured the spatial pattern of in situ observations in China and the variation trends in the northeast. In addition, the spatial patterns of SM obtained from CLM3.5/ObsFC matched reasonably with in situ observations, particularly across the north in summer. On the other hand, while most of the land models were able to represent the overall features of the regional SM geographical distributions, the absolute values, amplitudes and some local characteristics of space-time variations differed among them. These discrepancies were due to disparities in the representation of physical processes, land data and atmospheric forcing. For these reasons, CLM3.5/ ObsFC was able to reproduce regional characteristics and long-term trends of SM variations in China, with higher consistency in space-time features between CLM3.5/ObsFC simulations and in situ observations in the east due to the better quality of atmospheric forcing. In turn, the limitations of spatial density and data completeness of the in situ meteorological observations increased the uncertainty of the CLM3.5/ObsFC simulations (especially in western China). Because of the uncertainty in atmospheric simulations using general circulation models, numerical simulations that use observation-based atmospheric forcing and sophisticated land models are one of the most feasible approaches for investigating SM variations.

The results of the CLM3.5/ObsFC-simulated SM analysis reveal that the spatial pattern of SM is characterized by a decreasing gradient from the southeast to northwest and by alternate dry and wet zones. The major areas of low SM were located in the southern portion of Xinjiang Province and western Inner Mongolia, while the high values of SM were distributed over the Northeast Plain, the Huaihe River basin, the Yangzi River basin and the southeastern QinghaiTibetan plateau. The long-term SM variations were characterized by wetting trends over arid and humid regions and drying trends over semiarid regions. The volumetric percentage points of regionally averaged SM changed by $2.35 \%,-1.26 \%$ and $0.08 \%$ in the arid, semiarid and humid regions, respectively. The EOF and wavelet analyses also suggest that the trends and intensities of SM variations var- ied in the different regions, as did the effects of climate variables. The significant $\mathrm{SM}$ variations north of $35^{\circ} \mathrm{N}$ were likely to be a local response to global changes, and the direct causes need further study. Nevertheless, the SM variations indicate changes in the regional climate, water resources and environment.

This study showed that CLM3.5/ObsFC can represent the space-time characteristics and variation trends of SM in China. However, with respect to the absolute value, the CLM3.5/ObsFC-simulated SM had large systematic bias, which was enhanced in the west by the complex topography and increasing land heterogeneity. Therefore, we plan to improve the quality of the atmospheric forcing data and the representations of physical processes applied by CLM3.5, thereby enhancing the SM simulation in terms of absolute magnitude and spatial and temporal variations.

We thank all the reviewers for their constructive advice. This work was supported by the National Basic Research Program of China (2010 CB428404), the Key Program of the National Natural Science Foundation of China (40830956) and the Special Fund for Meteorological Scientific Research in Public Interest (GYHY201106028).

1 Namias J. Persistence of Mid-Tropospheric Circulations between Adjacent Months and Seasons. Rossby Memorial Volume. New York: Rockefeller Institute Press and Oxford University Press, 1958. 240-248

2 Manabe S. Climate and ocean circulation.I. Atmospheric circulation and hydrology of earths surface. Mon Weather Rev, 1969, 97: 739-774

3 Koster R D, Suarez M J, Higgins R W, et al. Observational evidence that soil moisture variations affect precipitation. Geophys Res Lett, 2003, 30, doi: 10.1029/2002g1016571

4 Xue Y, Sellers P J, Kinter J L, et al. A simplified biosphere model for global climate studies. J Climate, 1991, 4: 345-364

5 Dai A, Trenberth K E, Karl T R. Effects of clouds, soil moisture, precipitation, and water vapor on diurnal temperature range. J Climate, 1999, 12: 2451-2473

6 Vinnikov K Y, Robock A, Speranskaya N A, et al. Scales of temporal and spatial variability of midlatitude soil moisture. J Geophys ResAtmos, 1996, 101: 7163-7174

7 Koster R D, Dirmeyer P A, Guo Z C, et al. Regions of strong coupling between soil moisture and precipitation. Science, 2004, 305: 1138-1140

8 Seneviratne S I, Corti T, Davin E L, et al. Investigating soil moisture-climate interactions in a changing climate: A review. EarthSci Rev, 2010, 99: 125-161

9 Robock A, Vinnikov K Y, Srinivasan G, et al. The global soil moisture data bank. Bull Amer Meteorol Soc, 2000, 81: 1281-1299

10 Miller G R, Baldocchi D D, Law B E, et al. An analysis of soil moisture dynamics using multi-year data from a network of micrometeorological observation sites. Adv Water Resour, 2007, 30: 1065-1081

11 Kerr Y H. Soil moisture from space: where are we? Hydrogeol J, 2007, 15: 117-120

12 Chen H S, Xiong M M, Sha W Y. Simulation of land surface processes over China and its validation part I: soil temperature (in Chinese). Sci Meteorol Sin, 2010, 30: 621-630

13 Du C L, Liu X D, Wu W L. CLM3-simulated Chinese soil moisture during 1979-2003 and its possible response to global warming (in Chinese). Plateau Meteorol, 2008, 27: 463-473

14 Wang A, Zeng X D. Sensitivities of terrestrial water cycle simulations to the variations of precipitation and air temperature in China. J Geophys Res-Atmos, 2011, 116, doi:10.1029/2010JD014659 
15 Guo Z C, Dirmeyer P A, Hu Z Z, et al. Evaluation of the second global soil wetness project soil moisture simulations: 2 . Sensitivity to external meteorological forcing. J Geophys Res-Atmos, 2006, 111, doi:10.1029/2006JD007845

16 Guo Z C, Dirmeyer P A, Gao X, et al. Improving the quality of simulated soil moisture with a multi-model ensemble approach. Quart J Royal Meteorol Soc, 2007, 133: 731-747

17 Oki T, Nishimura T, Dirmeyer P. Assessment of annual runoff from land surface models using total runoff integrating pathways (trip). J Meteorol Soc Jpn, 1999, 77: 235-255

18 Huang $\mathrm{C} \mathrm{L}, \mathrm{Li} \mathrm{X}, \mathrm{Lu} \mathrm{L}$. Retrieving soil temperature profile by assimilating MODIS lst products with ensemble kalman filter. Remote Sens Environ, 2008, 112: 1320-1336

19 Reichle R H, Walker J P, Koster R D, et al. Extended versus ensemble kalman filtering for land data assimilation. J Hydrometeorol, 2002, 3: 728-740

20 Bonan G B. A land surface model (LSM version 1.0) for ecological, hydrological, and atmospheric studies: Technical Description and User's Guide [M]. PB-97-131494/XAB, National Center for Atmospheric Research, Boulder, CO (United States). Clim Glob Dyn Div, 1996

21 Dai Y J, Zeng Q C. A land surface model (IAP94) for climate studies part I: formulation and validation in off-line experiments. Adv Atmos Sci, 1997, 14: 433-460

22 Dickinson R, Henderson-Sellers A, Kennedy P. Biosphere-atmosphere transfer scheme (BATS) version 1 as coupled to the NCAR community climate model NCAR tech note, NCAR/TN387+ STR, 1993, 77

23 Dickinson R E, Oleson K W, Bonan G, et al. The Community Land Model and its climate statistics as a component of the Community Climate System Model. J Clim, 2006, 19: 2302-2324

24 Hack J J, Caron J M, Yeager S G, et al. Simulation of the global hydrological cycle in the CCSM Community Atmosphere Model version 3 (CAM3): Mean features. J Clim, 2006, 19: 2199-2221

25 Bonan G B, Oleson K W, Vertenstein M, et al. The land surface climatology of the Community Land Model coupled to the NCAR Community Climate Model. J Clim, 2002, 15: 3123-3149

26 Lawrence D M, Thornton P E, Oleson K W, et al. The partitioning of evapotranspiration into transpiration, soil evaporation, and canopy evaporation in a GCM: Impacts on land-atmosphere interaction. J Hydrometeorol, 2007, 8: 862-880

27 Thornton P E, Zimmermann N E. An improved canopy integration scheme for a land surface model with prognostic canopy structure. $\mathrm{J}$ Clim, 2007, 20: 3902-3923

28 Lawrence P J, Chase T N. Representing a new MODIS consistent land surface in the Community Land Model (CLM 3.0). J Geophys Res-Biogeosci, 2007, 112, doi:10.1029/2006JG000168

29 Niu G Y, Yang Z L, Dickinson R E, et al. A simple TOPMODELbased runoff parameterization (SIMTOP) for use in global climate models. J Geophys Res-Atmos, 2005, 110, doi:10.1029/2005JD006111

30 Niu G Y, Yang Z L, Dickinson R E, et al. Development of a simple groundwater model for use in climate models and evaluation with gravity recovery and climate experiment data. J Geophys Res-Atmos, 2007, 112, doi: 07110.01029/02006jd007522

31 Niu G Y, Yang Z L. Effects of frozen soil on snowmelt runoff and soil water storage at a continental scale. J Hydrometeorol, 2006, 7: 937-952

32 Oleson K W, Dai Y J, Bonan G, et al. Technical description of the Community Land Model (CLM), NCAR Tech. Note NCAR/Tn-461+ Str, Natl Cent For Atmos Res, Boulder, Colo. 2004, 173

33 Oleson K W, Niu G Y, Yang Z L, et al. Improvements to the Community Land Model and their impact on the hydrological cycle. $\mathrm{J}$ Geophys Res-Biogeosci, 2008, 113, doi:10.1029/2007JG000563
34 Zeng X B, Decker M. Improving the numerical solution of soil moisture-based Richards equation for land models with a deep or shallow water table. J Hydrometeorol, 2009, 10: 308-319

35 Decker M, Zeng X. Impact of modified Richards equation on global soil moisture simulation in the Community Land Model (CLM3. 5). J Adv Model Earth Syst, 2009, 1, doi:10.3894/JAMES.2009.1.5

36 Sakaguchi K, Zeng X B. Effects of soil wetness, plant litter, and under-canopy atmospheric stability on ground evaporation in the Community Land Model (CLM3.5). J Geophys Res-Atmos, 2009, 114, doi:10.1029/2008JD010834

37 Flanner M G, Zender C S. Linking snowpack microphysics and albedo evolution. J Geophys Res-Atmos, 2006, 111, doi:10.1029/ 2005JD006834

38 Sheffield J, Goteti G, Wood E F. Development of a 50-yr highresolution global dataset of meteorological forcings for land surface modeling. J Clim, 2006, 19: 3088-3111

39 Li M X. Modeling study on the variation of soil moisture in China (in Chinese). Dissertation for the Doctoral Degree. Beijing: Graduate University of Chinese Academy of Sciences, 2010

$40 \mathrm{Li} \mathrm{M} \mathrm{X,} \mathrm{Ma} \mathrm{Z} \mathrm{G.} \mathrm{Comparisons} \mathrm{of} \mathrm{simulations} \mathrm{of} \mathrm{soil} \mathrm{moisture}$ variations in the yellow river basin driven by various atmospheric forcing data sets. Adv Atmos Sci, 2010, 27: 1289-1302

41 Wagner W, Lemoine $\mathrm{G}$, Rott $\mathrm{H}$. A method for estimating soil moisture from ERS scatterometer and soil data. Remote Sens Environ, 1999, 70: 191-207

42 Wagner W, Scipal K, Pathe C, et al. Evaluation of the agreement between the first global remotely sensed soil moisture data with model and precipitation data. J Geophys Res-Atmos, 2003, 108, doi:10.1029/2003JD003663

43 Njoku E G, Jackson T J, Lakshmi V, et al. Soil moisture retrieval from AMSR-E. IEEE Trans Geosci Remote Sens, 2003, 41: 215-229

44 Rodell M, Houser P R, Jambor U, et al. The Global Land Data Assimilation System. Bull Amer Meteorol Soc, 2004, 85: 381-394

45 Fan Y, Van Den Dool H. Climate prediction center global monthly soil moisture data set at 0.5 degrees resolution for 1948 to present. J Geophys Res-Atmos, 2004, 109, doi:10.1029/2003JD004345

46 Zuo Z Y, Zhang R H. The spring soil moisture and the summer rainfall in eastern china. Chinese Sci Bull, 2007, 52: 3310-3312

47 Zhang W J, Zhou T J, Yu R C. Spatial distribution and temporal variation of soil moisture over China part I: Multi-data intercomparison (in Chinese). Chin J Atmos Sci, 2008, 32: 581-597

$48 \mathrm{Hu}$ Y M, Ding Y H, Liao F. An improvement on summer regional climate simulation over East China: Importance of data assimilation of soil moisture. Chinese Sci Bull, 2010, 55: 865-871

49 Sun C H, Li W J, Zhang Z Q, et al. Distribution and variation features of soil humidity anomaly in Huaihe River basin and its relationship with climatic anomaly (in Chinese). J Appl Meteorol Sci, 2005, 16: 129-138

$50 \mathrm{Ma} \mathrm{Z} \mathrm{G,} \mathrm{Fu} \mathrm{C} \mathrm{B.} \mathrm{Some} \mathrm{evidence} \mathrm{of} \mathrm{drying} \mathrm{trend} \mathrm{over} \mathrm{northern} \mathrm{china}$ from 1951 to 2004. Chinese Sci Bull, 2006, 51: 2913-2925

51 Guo W D, Ma Z G, Yao Y H. Regional characteristics of soil moisture evolution in northern China over recent 50 years ( in Chinese). Acta Geogr Sin, 2003, 58: 83-90

52 Liu S X, Mo X G, Li H B, et al. Spatial variation of soil moisture in China: Geostatistical characterization. J Meteorol Soc Jpn, 2001, 79: 555-574

53 D'odorico P, Porporato A. Preferential states in soil moisture and climate dynamics. Proceedings of the National Academy of Sciences of the United States of America, 2004, 101: 8848-8851

54 Pan Y X, Wang X P. Factors controlling the spatial variability of surface soil moisture within revegetated-stabilized desert ecosystems of the tengger desert, northern China. Hydrol Processes, 2009, 23: 1591-1601

Open Access This article is distributed under the terms of the Creative Commons Attribution License which permits any use, distribution, and reproduction in any medium, provided the original author(s) and source are credited. 